Military Technical College

Kobry El-Kobbah,

Cairo, Egypt

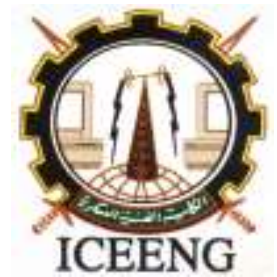

ICEENG $11^{\text {th }}$ International Conference

on Electrical Engineering

ICEENG 2018

\title{
ISLANDING DETECTION OF MICROGRID USING DECISION-TREE APPROACH
}

\author{
Ahmed Ezzat Mohamed*, Basem Elhady* and Abdelazeem A. Abdelsalam
}

\begin{abstract}
Microgrids are becoming more popular and irresistible options for increasing system reliability and operation. One of the most important challenges in microgrid operation is the unintentional islanding occurrence. Unintentional islanding can cause serious safety hazards and technical issues. Islanding detection methods can be classified into active and passive methods. The proposed passive approach is based on Discrete Fourier Transform and decision-tree for detecting the intentional and nonintentional microgrid islanding. The proposed microgrid islanding detection approach is tested on a microgrid equipped with synchronous generator-based DGs. The proposed method is capable of detecting islanding with a speed accuracy less than three cycles from the islanding inception. The results of proposed method are compared with other existing techniques in terms of fast islanding detection, dependability, security and accuracy. The simulation results show that the proposed approach is effective in detecting islanding phenomenon possesses compared to existing islanding detection techniques.
\end{abstract}

\section{KEY WORDS}

Distributed Generators, Microgrids, Islanding Detection, Feature extraction, Decision Tree.

\section{NOMENCLATURES}

\begin{tabular}{|c|c|c|c|}
\hline ANFIS & $\begin{array}{l}\text { Adaptive neuro fuzzy inference } \\
\text { system. }\end{array}$ & $\begin{array}{l}\text { FLC } \\
\text { K-NN }\end{array}$ & $\begin{array}{l}\text { Fuzzy logic control. } \\
\text { K nearest neighbor. }\end{array}$ \\
\hline AUC & Area under curve. & NB & Naïve bayes. \\
\hline AIS & Artificial immune system. & PCC & Points of common \\
\hline ANN & Artificial neural networks. & & couplings. \\
\hline DT & Decision tree. & ROCOF & Rate of change of \\
\hline DFT & Discrete Fourier transform. & & frequency. \\
\hline DG & Distributed generator. & $\mathrm{ROC}$ & Receiver operating \\
\hline EPS & Electric power system. & & characteristic. \\
\hline FT & Fourier transform. & SVM & Support vector machine. \\
\hline & & WT & Wavelet transforms. \\
\hline
\end{tabular}

* Dept. of Electrical Engineering, Suez Canal University, Ismailia, Egypt. 


\section{Introduction}

Microgrid is a grouping of DGs and loads which operates connected to the electric utility grid, or operates disconnected as physical or financial policies dictate. Microgrid has two kinds of DGs; inverter-based DGs as solar cell, wind turbine, and storage battery, and others such as micro steam turbine and synchronous generator and depend on the principle of generators. The big problem with DGs in Microgrids is islanding. The islanding definition in IEEE Std.1547 is an area of EPS which is energized only by one or more local EPSs through its PCC while that part is electrically isolated from main grid" [1]. IEEE Std. 1547 recommends that the distributed generation must have been separated in a time not more than 2 seconds in islanding Microgrids" [2].

The event of islanding has two kinds: intentional islanding and non-intentional islanding. First kind of islanding is a planned islanding as the maintenance is needful for the particular part of microgrid and disconnect this part from original grid. Where in nonintentional islanding, it is not planned to disconnect intentionally but it is disconnecting due to any types of fault [3]. There are some reasons that make fast detection for islanding phenomena is very important as shown in [4]:

- It creates safety hazard to the person working for maintenance. Thus, it may threat line worker's safety.

- It causes severe fluctuations in voltage and frequency of the electrical network, which cause a failure and damage of electrical equipment.

- A synchronous reclosing problem between the DG and main grid reconnection. This may cause fatal damaging the equipment or re-tripping lines.

- The sensitive equipment during islanding may have malfunctioning because of the degradation in the quality of the power system.

There are two categories of islanding detection approaches which are local technique and remote detection techniques. Local islanding detection moreover splitted into passive, active, hybrid and intelligent detection methods for islanding phenomenon [5]. Local techniques depend on system parameters measurement at the DG site, whereas, the other one remote technique depend on the interactive communications from the original grid and the DG site and vice versa [6].

The retrieve parameters (voltage, frequency) at the DG terminals or PCC are used in passive method for islanding detection, then comparing this measured parameters with a prearranged threshold limit for the detecting islanding. Some of passive techniques include voltage magnitude variation, voltage unbalance [7], method based on impedance to reserve overlapped ROCOF relay [8], ROCOF [9] and frequency with damping agent of output frequency [10]. The passive techniques have advantage of that the power quality of the electrical power system don't affected by it. Hence, power quality issues, such as electrical noise, voltage dip, and spikes do not appear. In the other side those techniques suffer from the carefully setting of thresholds values where low threshold value lead to have nuisance tripping, while high threshold value fail to achieve islanding detection. Those disadvantages can be overcome by using active islanding detection techniques. 
The basic of active islanding techniques depend on the usage of high frequency signals to disturb the system variables, such as measured frequencies and voltages to make detection of the islanding. When the Microgrid is grid connected; this connection will cause variance in system parameters. Islanded mode makes the system observes a significant divergence in system parameter, which will lead to the detection of islanding. Approaches using active techniques in islanding detection include but not limited to the voltage negative sequence component injection [11], method depended on voltage phase angle of inverter based DG [12], analysis of sandia frequency-shift technique [13], current injection [14], current negative sequence component injection [15], injection of a high frequency signal [16], virtual capacitor [17] and phase locked loop perturbation [18]

When the two mentioned above techniques are combined resulting hybrid islanding detection. When a passive approach is failed to detect islanding events, Active techniques are come to achieve detection of the islanding. Hybrid techniques include but not limit to method based on measuring current and active power of DG circuit breakers [19], using rate-of-change-of-reactive power with load planning connection [20], frequency versus slip-mode frequency-shift and reactive power [21] real power shift and rate-of-voltage change in [22].

Islanding event must be detected as accurately and quickly as possible. So, methods using intelligent techniques are attractive for detecting and classifying the islanding condition. The hidden features of the retrieved signals can be obtained by implementing techniques of the signal processing for extracting some of effective features, then those features are can be used to have an input data to the artificial intelligent classifier to fulfill the islanding detection event. The implementation of the techniques of signal processing such as FT, WT and S-transform allows for extraction of the signatures of every retrieved signals to feed classifier with input data. The artificial intelligent classifier techniques include SVM technique [23], FLC [24], ANN [25], ANFIS [26] and AIS [27]. The advantage of artificial intelligent classifier techniques is their ability of solving nonlinear multi objective problems, which can't be solved by the conventional methods.

The approach in this paper used a passive approach for detecting island problem based on artificial intelligent technique to extract a unique set of decisive system features extracted from measured parameters at DG terminals. The decision tree based classifier is utilized for detecting and classifying event specific signatures associated with islanding events. The set of decisive system features is selected to enhance islanding detection accuracy under different system operating and loading conditions. The proposed microgrid islanding detection approach is simulated on a Microgrid model equipped with synchronous generator-based DGs. Running the simulation and take the events data base to train the decision tree classifier using the database obtained from simulations.

\section{II. methodology of the proposed approach}

The proposed approach is consisting of two stages; i) extracting some features from the measured voltage and currents at the target DG, and ii) classifying event specific with these features using a DT based classifier for detection of islanding events. The proposed model is shown in Fig. 1. 
Fig. 1. The proposed islanding detection model

\section{A) Features Extraction}

DFT based pre-processor is applied to evaluate fundamental phasor values and consequent features. Phasor estimation includes measurement of parameters such as voltage amplitude, current amplitude, frequency and phase angle. From these parameters, several features can be extracted. The proposed model uses synchronous transformation-based phasor estimation of the measured instantaneous voltage and current signals for computing features. Fig 2 shows the block diagram for feature extraction stage and the complete feature extractor using DFT pre-processor which is interfaced to DT for final decision-making is cleared in Fig 3. In this approach, four features are extracted that are affected during islanding and can be measured locally and they are as follows:

$X_{1}=\Delta f$, the frequency deviation $(\mathrm{Hz})$.

$X_{2}=\Delta V$, the rms voltage deviation in (pu).

$X_{3}=\Delta \phi$, the change in the phase angle difference between voltage and current.

$X_{4}=d \phi / d t$, the rate of change of phase angle difference.

Fig. 2. DFT block diagram

Fig. 3. DFT detailed Matlab Simulink model

\section{B) Decision Tree (DT)}

DT is built from a dataset called a training data which containing $m$ dimensional feature vectors and their class values. Each branch downward from the node identifies to one of the possible values of this characteristic. Classification starting at the root node of the tree, testing the specific feature by this node, then moving down the tree branch according to the value of the characteristic. The process is iterated using the training events associated with every descendant node to choose the preferable characteristic to test at that point in a tree.

In this paper, islanding detection can be identified by the decision tree using the following steps:

- Simulating the model network.

- Measuring the voltage and current at every DG location at every situation.

- Simulating events (intentional or unintentional) and creating a database i.e. pattern vector $X$ of the deviations.

- Analyzing the database generated from the simulation and determining the feature extractions of the parameters.

- Using DT, classify the data into islanding \& non-islanding state and store pattern vector $\mathrm{X}$ along with the corresponding class $\mathrm{Y}$ in the database. 


\section{III. the Test system}

The studied model scheme along with the Microgrid components is shown in Fig. 4. The Matlab Simulink model of the test system shown in Fig. 5. The instantaneous voltage and current signals are monitored using current transformer / potential transformer at target DG location and then through DFT pre-processor. DFT estimates phase and frequency, fundamental amplitude for voltage and current and other related features. These extracted features are used to train the DT classifier model to have the best final decision. The detailed parameters of the model components are summarized in Tables 1-3.

Fig. 4. Single line diagram of the test system

Fig. 5. Matlab model of test system

Table 1. Line parameters

Table 2. Load parameters

Table 3. DGs parameters

The tested model consists of synchronous generator-based DG units as shown in Fig. 4. DG which used in the proposed model is a salient pole synchronous machine with brushless excitation. Excitation system is combined of a small synchronous machine connected on the main shaft and current rectification is executed by a rotating diode bridge fixed on the same shaft, feeding DC power to the synchronous generator field. Synchronous generator and the exciter are coupled mechanically using speed as mechanical input for the exciter machine.

\section{IV. simulation results}

In this paper, an elaborated test system on a grid connected Microgrid model has carried out to assess the effectiveness of the used approach using Matlab Simulink. The proposed method is simulated according to some steps which shown in Fig. 1 as follows:

\section{A) Running The Model and Recording Measurements}

The process starts with retrieving voltage and current signals at the DG end for islanding and non-islanding conditions and, the phasor estimation is performed using synchronous transformation based estimation algorithm. Initially the instantaneous current and voltage signals are fed to the sampling device and, sampled $V_{a b c}$ and $l_{a b c}$ are cascaded to the synchronous transformation based phasor estimation algorithm to estimate $V_{p}$ and $I_{p}$ and phase angle difference. The system model is simulated at 1.0 $\mathrm{kHz}$ (20 samples per cycle on $50 \mathrm{~Hz}$ base frequency).

\section{B) Training for Decision Tree Classifier}


By recording measurements, a training matrix is built and it consists of four columns for extracted features and one column for the response that has zeros for non-islanding and ones for islanding.

Using classifier application in Matlab to make training by two different testing methods i) K-fold cross effectiveness and ii) Holdout effectiveness. K-fold cross method divides the data base into $\mathrm{K}$ subsets and make iterations in number of $\mathrm{K}$. In each iteration, (K1) subsets used for training sets and a single subset as validation set. Every $K$ subsets is used for validation set once in the process and results over $\mathrm{K}$ iterations are averaged to reach the last result. The proposed technique simulated at choosing value of 5 -fold cross validation as a classifier validation. In Holdout validation method, entire dataset is divided into a learning set for training and a test set for testing classifier. This approach uses amount $80 \%$ of the data set for training set and $20 \%$ for test.

\section{C) Checking Training Performance}

1) Check performance per class in the confusion matrix

The confusion matrix diagram is used to understand how the currently selected classifier performed in each class. The confusion matrix helps in identifying the areas where the classifier has Poor performance. In confusion matrix, shown in Fig. 6, the rows have the true category, while columns have the predicted category. The cells is the place where the real class and prediction class are assigned. If the cells color is green, the classifier has performed well and classified observations of this true class correctly and verse vice.

Fig. 6. Confusion matrix diagram

Fig. 7. Parallel coordinates diagram

Fig. 8. ROC curve

Fig. 9. DT generated during training

2) Investigate features in the parallel coordinates diagram

This diagram is used to understand relationships between features and identify useful predictors for separating classes. Training data and misclassified points are visualized on the parallel coordinate's diagram. Misclassified points are appear as dashed in Fig. 7.

3) Receiver Operating Characteristic (ROC) Curve ROC it is a curve which shows a graph for to values which is a true positive versus false positive rate for the classifier. In Fig. 8. Shows the values of the false positive and the true positive rate for the classifier. To understand the meaning of ROC curve we take an example like a false positive rate of 0.35 indicates that the classification incorrectly assigns $35 \%$ of positive status tracking. A positive force of 0.75 indicates that the classifier correctly allocates $75 \%$ of the positive class observations. The ideal result without the wrong points is the rectangular angle in the upper left corner of the curve. A bad result, which is no more than a coincidence, is a 45-degree line. AUC number is a measure of the overall quality of the classifier. Classifier performance will be better if the AUC indicates a larger value. 
After recording data, training decision tree classifier and checking the performance of the decision tree classifier, the optimal decision tree is identified and is seen in Fig. 9.

\section{D) Results and Discussions}

In the proposed method we take each cases of islanding intentional islanding by opening each $\mathrm{CB}$ and found its effect on the DGs, other case is non-intentional islanding by making a linear fault with $R=30 \Omega$.

1) Intentional islanding

When the main station breaker $\mathrm{CB} 0$ is opened at $\mathrm{t}=6.5 \mathrm{~s}$, for maintenance or any other normal operation switching, the proposed approach detects the islanding inception at DG1, DG2, DG3 and DG4 as shown in Fig. 10, where 0 refers non-islanding and 1 refers to islanding inception.

When $C B 1$ is opened at $t=6.5 \mathrm{~s}$, the results in Fig. 11 show that DG1 is islanded while the others DGs 2, 3 and 4 are non-islanded.

When CB2 is opened at $t=6.5 \mathrm{~s}$, the proposed approach detects that DG2 is islanded and others are non-islanded, as shown in Fig. 12.

In Fig. 13, the proposed approach gives the decision of islanding for DG3 and nonislanding of others DGs when CB3 is opened at $\mathrm{t}=6.5 \mathrm{~s}$.

Finally, Fig. 14 shows that DG4 is islanded and DGs 1, 2 and 3 are non-islanded when CB4 is opened at $t=6.5 \mathrm{~s}$.

Fig. 10. Islanding decision when $\mathrm{CB} 0$ is opened

Fig. 11. Islanding decision when $C B 1$ is opened

Fig. 12. Islanding decision when $C B 2$ is opened

Fig. 13. Islanding decision when $C B 3$ is opened

Fig. 14. Islanding decision when CB4 is opened

2) Non-Intentional islanding

When a fault occurs near to $\mathrm{CB} 0$ and at $\mathrm{t}=4.5 \mathrm{~s}$, the proposed approach decides that all DGs are islanded from the instant of fault inceptions, as shown in Fig 15, and this means that this microgrid will be in autonomous mode.

In Fig. 16, the results show that DG1 is islanded and others are non-islanded, when a fault incepts close to $\mathrm{CB} 1$ at $\mathrm{t}=4.5 \mathrm{~s}$.

Also when the fault occurs close to CB2 and the instant of $t=4.5 \mathrm{~s}$, the approach classifies that DG2 is islanded and others are non-islanded, as depicted in Fig. 17. 
When CB3 is close to a fault location occurs at $t=4.5 \mathrm{~s}$, the results shown in Fig. 19 illustrate that DG3 is islanded and other DGs are non-islanded.

The proposed approach detects that DG4 is islanded and other DGs are non-islanded from the instant of fault inception close to CB4 at $\mathrm{t}=4.5 \mathrm{~s}$, as shown in Fig. 19.

Fig. 15. Islanding decision when a fault occurs near to $\mathrm{CB} 0$

Fig. 16. Islanding decision when a fault is close to CB1

Fig. 17. Islanding decision when a fault occurs near to $\mathrm{CB} 2$

Fig. 18. Islanding decision when a fault occurs near to CB3

Fig. 19. Islanding decision when a fault occurs near to CB4

\section{E) Comparisons}

Table 4 shows a comparison between the performance of proposed islanding detection approach based DT classifier, NB and K-NN classifiers for islanding detection in four indices of dependability, security, accuracy and fast islanding detection (time index). The results show that the superiority of the proposed approach in terms of fast detection where it requires $50 \mathrm{~ms}$ to detect the islanding or non-islanding operation mode with $99.5 \%$ accuracy.

Table 4. Comparison between proposed approach, NB, and K-NN

\section{CONCLUSIONS}

The proposed islanding detection approach for Microgrids operation is proposed in this paper. This approach utilizes set of system features and uses DT based classifier for pattern recognition and classification of many types of system events, intentional or non-intentional, for islanding detection. The proposed approach is tested on a microgrid equipped with synchronous generator-based DGs. The suggested method is likely detecting islanding with a speed accuracy less than three cycles from the islanding occurrence. The results of proposed method are compared with other techniques in terms of fast islanding detection, dependability, security and accuracy. Examples of patterns show the superiority of effective detection of islanding phenomenon in compare with other islanding detection techniques.

\section{References}

[1] G. Bayrak and E. Kabalcı, "Implementation of a new remote islanding detection method for wind-solar hybrid power plants", Renew Sustain Energy Reviews, vol. 58, pp. 1-15 (2016).

[2] IEEE Application Guide for IEEE Std 1547(TM), "IEEE Standard for Interconnecting Distributed Resources with Electric Power Systems", IEEE Std 1547.2-2008, pp. 1-217 (2009). 
[3] J. Laghari, H. Mokhlis, M. Karimi, A. Bakar and H. Mohamad, "An islanding detection strategy for distribution network connected with hybrid DG resources", Renewable and Sustainable Energy Reviews, vol. 45, pp. 662-676 (2015).

[4] H. Samet, F. Hashemi and T. Ghanbari, "Minimum non detection zone for islanding detection using an optimal Artificial Neural Network algorithm based on PSO", Renewable and Sustainable Energy Reviews, vol. 52, pp. 1-18, (2015).

[5] D. Velasco, C. Trujillo, G. Garcer and E. Figueres, "Review of anti-islanding techniques in distributed generators", Renewable and Sustainable Energy Reviews, vol. 14, no. 6, pp. 1608-1614 (2010).

[6] J.A. Laghari, H. Mokhlis, M. Karimi, A.H.A. Bakar and H. Mohamad, "Computational Intelligence based techniques for islanding detection of distributed generation in distribution network: A review", Energy Conversion and Management, vol. 88, pp. 139-152 (2014).

[7] E. Kamyab and J. Sadeh, "Islanding detection method for photovoltaic distributed generation based on voltage drifting", in IET Generation, Transmission \& Distribution, vol. 7, no. 6, pp. 584-92 (2013).

[8] K. Jia, T. Bi, B. Liu, D. Thomas and A. Goodman, "Advanced islanding detection utilized in distribution systems with DFIG", International Journal of Electrical Power \& Energy Systems, vol. 63, pp. 113-123 (2014).

[9] W. Freitas, Wilsun Xu, C. M. Affonso and Zhenyu Huang, "Comparative analysis between ROCOF and vector surge relays for distributed generation applications", in IEEE Transactions on Power Delivery, vol. 20, no. 2, pp. 1315-1324 (2005).

[10] H. Zeineldin, T. Abdel-Galil, E. El-Saadany, M. Salama, "Islanding detection of grid connected distributed generators using TLS-ESPRIT", Electric Power Systems Research, vol. 77, no. 2, pp. 155-162 (2007).

[11] Byeong-Heon Kim, S. K. Sul and Chun-Ho Lim, "Anti-islanding detection method using Negative Sequence Voltage", Proceedings of The 7th International Power Electronics and Motion Control Conference, Harbin, China, pp. 604-608 (2012).

[12] H. Pourbabak and A. Kazemi. "A new technique for islanding detection using voltage phase angle of inverter-based DGs", International Journal of Electrical Power \& Energy Systems, Vol. 57, pp. 198-205 (2014).

[13] O. Arguence, B. Raison and F. Cadoux, "Comments on "Impact of Load Frequency Dependence on the NDZ and Performance of the SFS Islanding Detection Method", in IEEE Transactions on Industrial Electronics, vol. 64, no. 9, pp. 7277-7279 (2017).

[14] G. Hernandez-Gonzalez and R. Iravani, "Current injection for active islanding detection of electronically-interfaced distributed resources", in IEEE Transactions on Power Delivery, vol. 21, no. 3, pp. 1698-1705 (2006).

[15] N. D. Tuyen and G. Fujita, "Negative-sequence Current Injection of Dispersed Generation for Islanding Detection and Unbalanced Fault Ridethrough", Universities' Power Engineering Conference (UPEC), Proceedings of 2011 46th International, Soest, Germany, pp. 1-6 (2011).

[16] D. Reigosa, F. Briz, C. Blanco, P. García and J. Manuel Guerrero, "Active Islanding Detection for Multiple Parallel-Connected Inverter-Based Distributed Generators Using High-Frequency Signal Injection", in IEEE Transactions on Power Electronics, vol. 29, no. 3, pp. 1192-1199 ( 2014).

[17] W-J. Chiang, H-L. Jou and J-C. Wu, "Active islanding detection method for inverter- based distribution generation power system", International Journal of Electrical Power \& Energy Systems, Vol. 42, no. 1, pp. 158-166 (2012). 
[18] D. Velasco, C. Trujillo, G. Garcera and E. Figueres, "An Active Anti-Islanding Method Based on Phase-PLL Perturbation", in IEEE Transactions on Power Electronics, vol. 26, no. 4, pp. 1056-1066 (2011).

[19] G. Bayrak and M. Cebeci, "A novel anti islanding detection method for grid connected fuel cell power generation systems", International Journal Hydrogen Energy, vol. 39, no. 16, pp. 8872-8880 (2014).

[20] J. Laghari, H. Mokhlis, A. Bakar and M. Karimi," A new islanding detection technique for multiple mini hydro based on rate of change of reactive power and load connecting strategy", Energy Convers Manage, vol. 76, pp. 215-224 (2013).

[21] S. Akhlaghi, A. A. Ghadimi and A. Akhlaghi, "A novel hybrid islanding detection method combination of SMS and Q-f for islanding detection of inverter- based DG"' 2014 Power and Energy Conference at Illinois (PECI), Champaign, IL, pp. 1-8 (2014).

[22] P. Mahat, Z. Chen and B. Bak-Jensen, "A hybrid islanding detection technique using average rate of voltage change and real power shift", 2009 IEEE Power \& Energy Society General Meeting, Calgary, AB, pp. 1-1 (2009).

[23] S. Mohanty, P. Ray, N. Kishor and B. Panigrahi, "Classification of disturbances in hybrid DG system using modular PNN and SVM", International Journal of Electrical Power \& Energy Systems, vol. 44, no. 1, pp. 764-777 (2013).

[24] L. Shi and F. Wu, "An islanding detection algorithm based on fuzzy adaptive phase drift control", 2013 IEEE International Conference on Information and Automation (ICIA), Yinchuan, pp. 225-229 (2013).

[25] A. Abd-Elkader, D. Allam and E. Tageldin, "Islanding detection method for DFIG wind turbines using artificial neural networks", International Journal of Electrical Power \& Energy Systems, vol. 62, pp. 335-343 (2014).

[26] H. Shayeghi and B. Sobhani, "Zero NDZ assessment for anti-islanding protection using wavelet analysis and neuro-fuzzy system in inverter based distributed generation", Energy Convers Manage, vol. 79, pp. 616-625 (2014).

[27] Guiliang Yin, "A Distributed Generation Islanding Detection Method Based on Artificial Immune System", 2005 IEEE/PES Transmission \& Distribution Conference \& Exposition: Asia and Pacific, Dalian, pp. 1-4 (2005). 


\section{A. Figures}

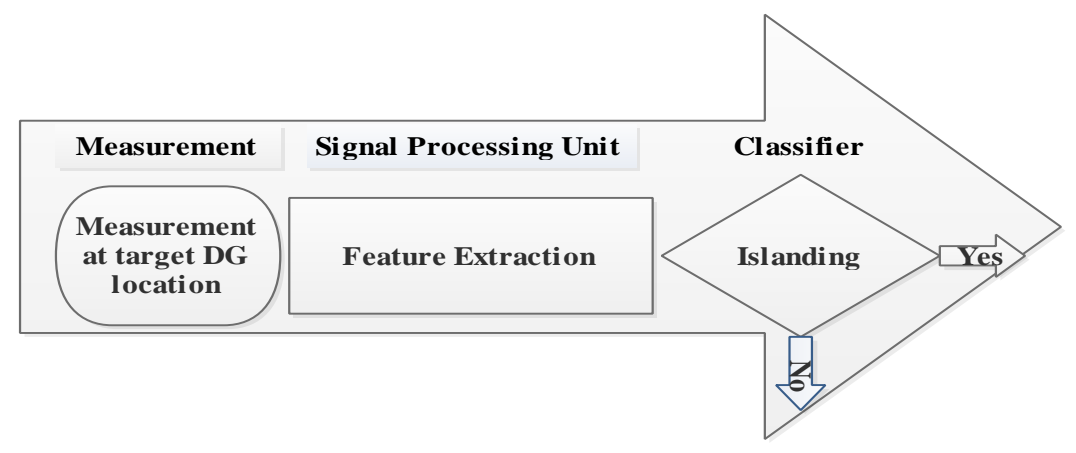

Fig. 1. The proposed islanding detection model

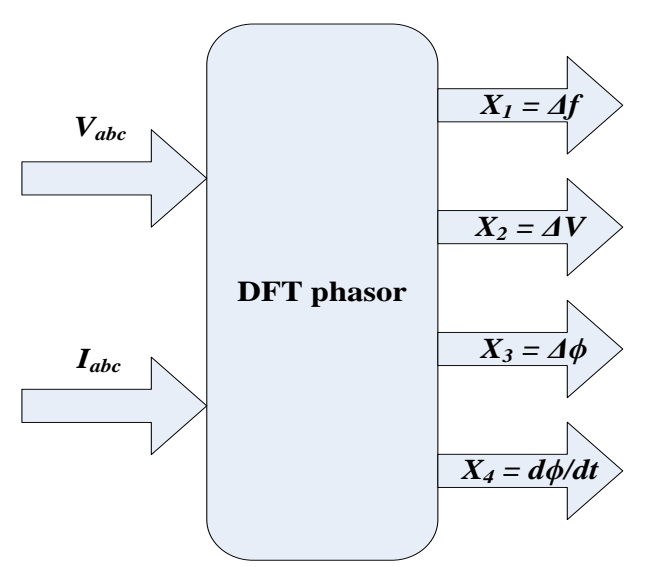

Fig. 2. DFT block diagram

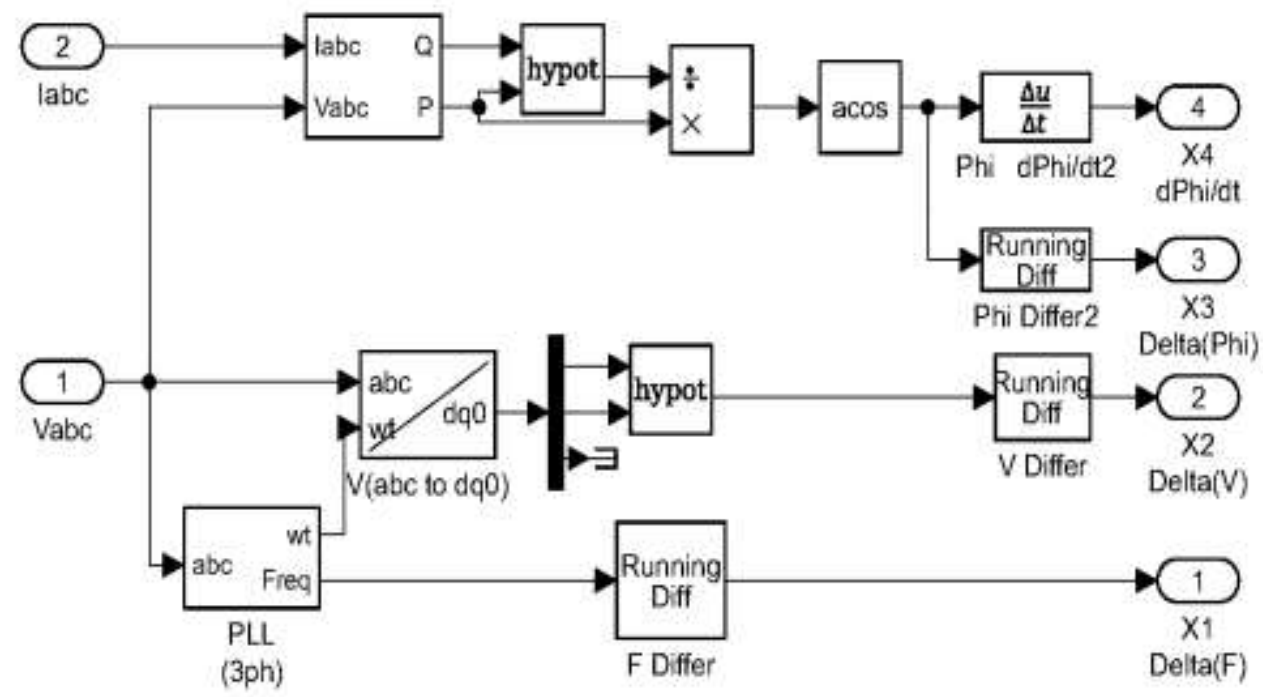

Fig. 3. DFT detailed Matlab Simulink model 


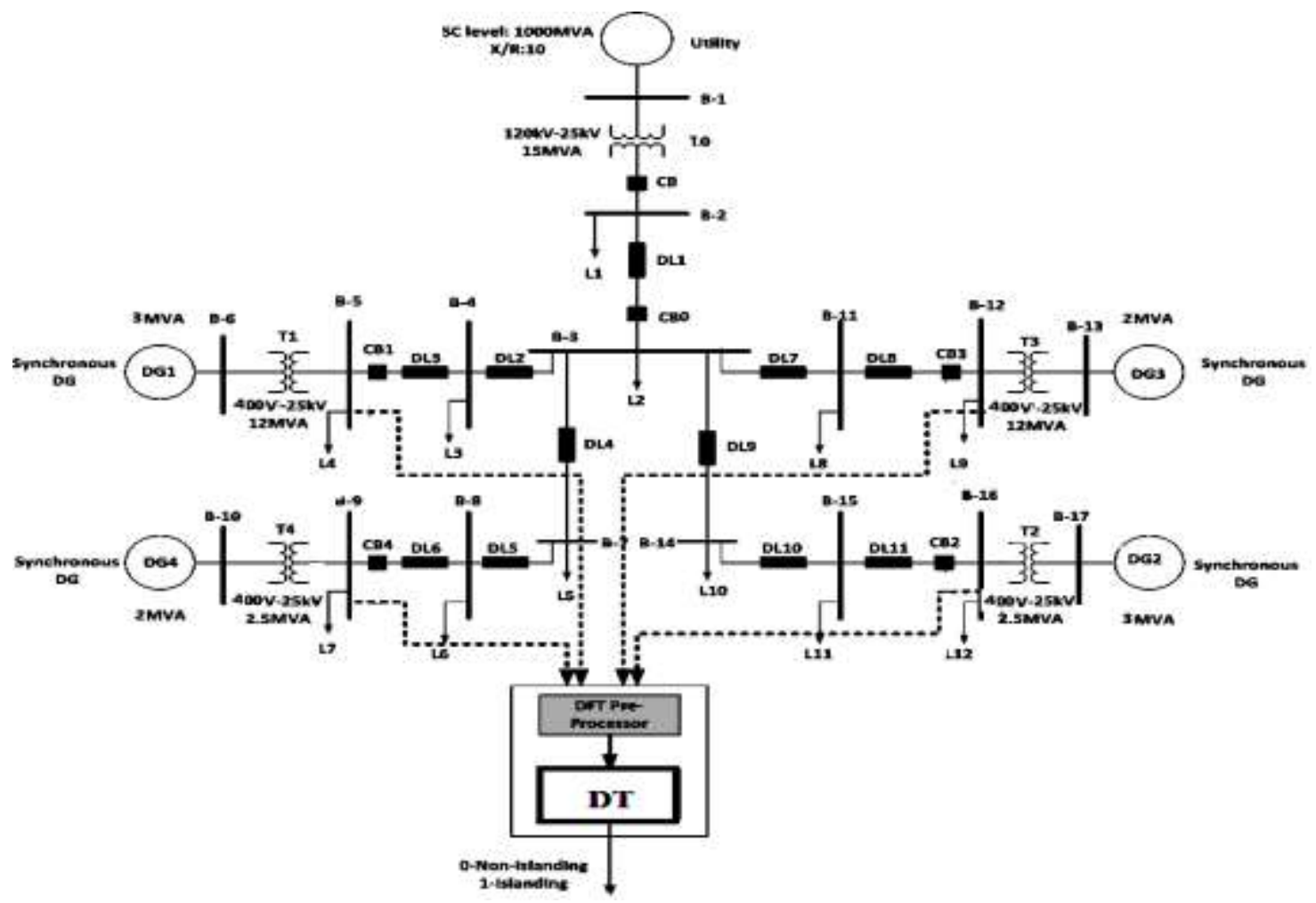

Fig. 4. Single line diagram of the test system 


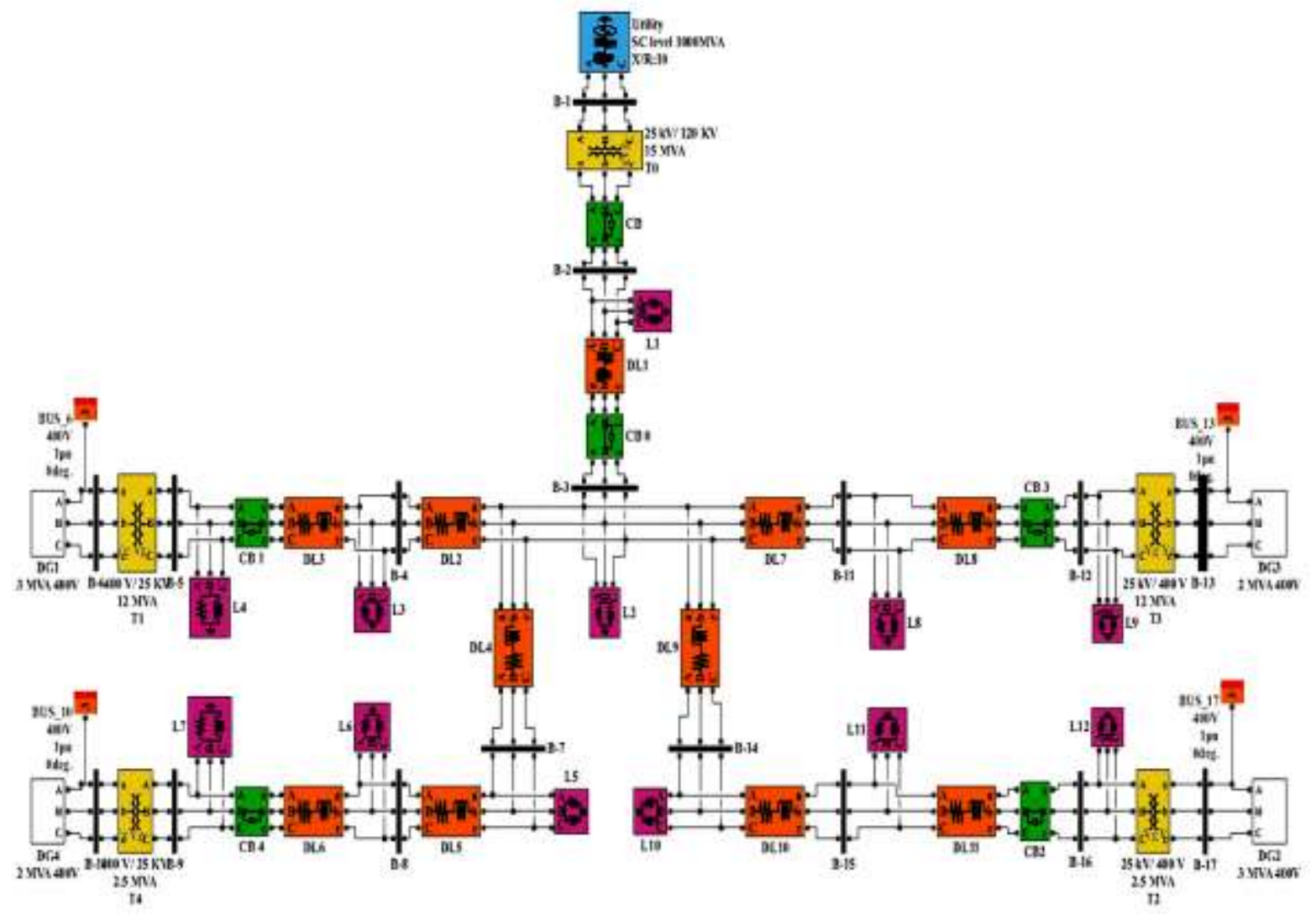

Fig. 5. Matlab model of test system

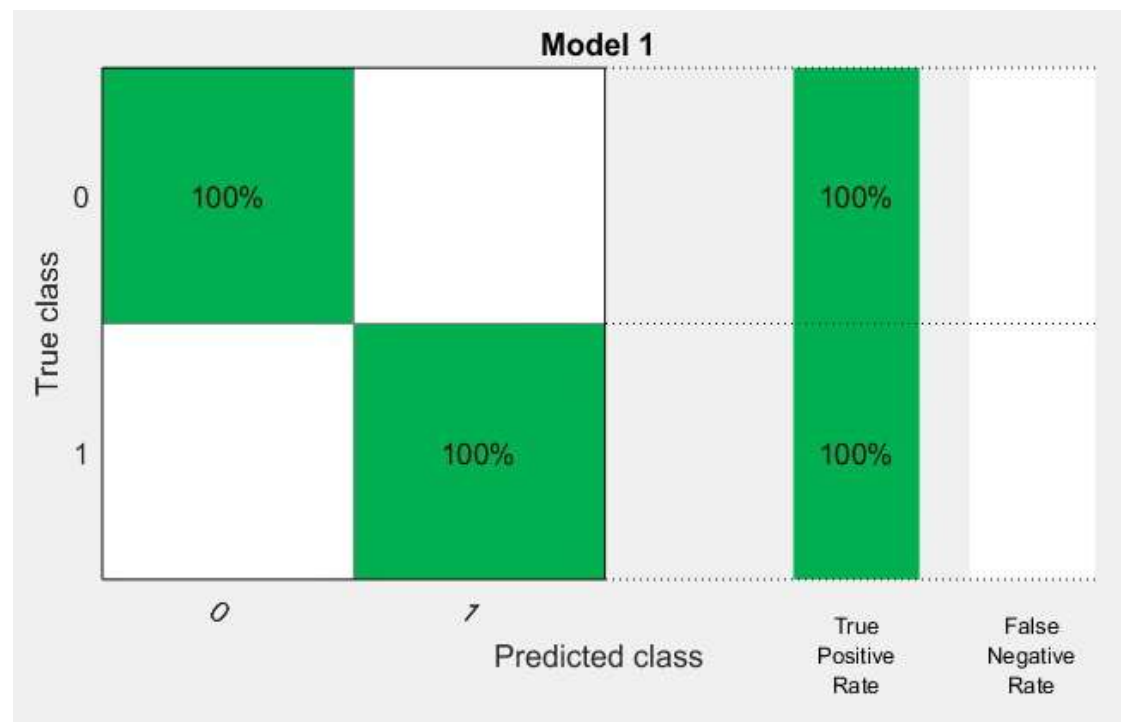

Fig. 6. Confusion matrix diagram 


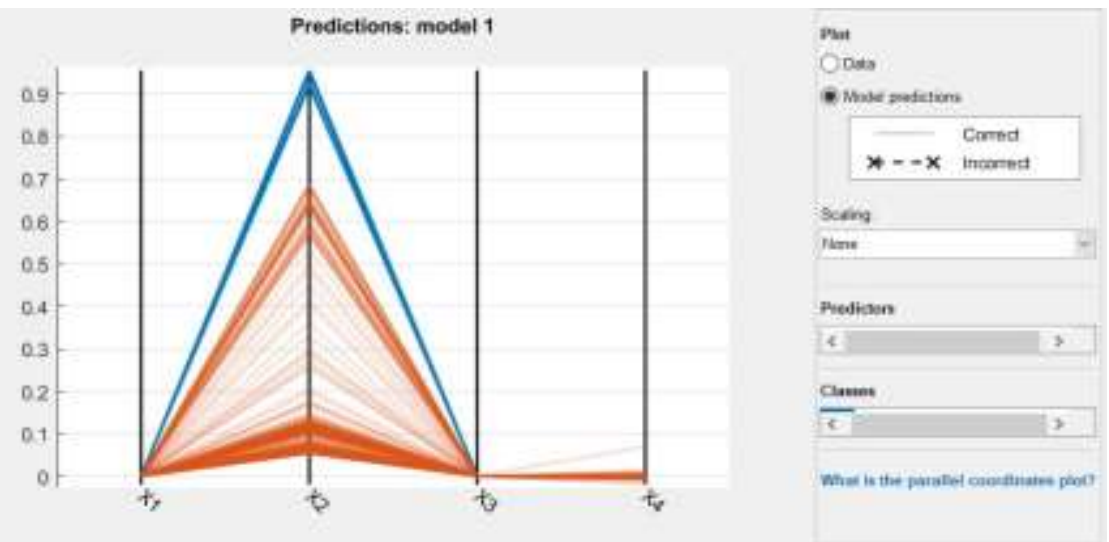

Fig. 7. Parallel coordinates diagram

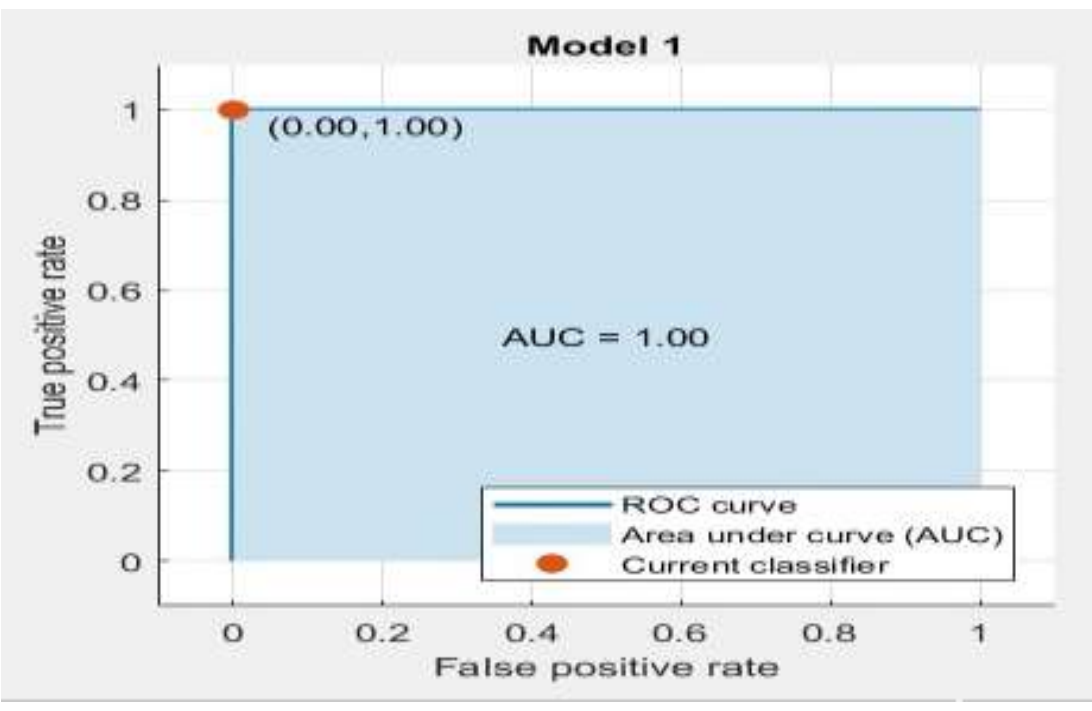

Fig. 8. ROC curve

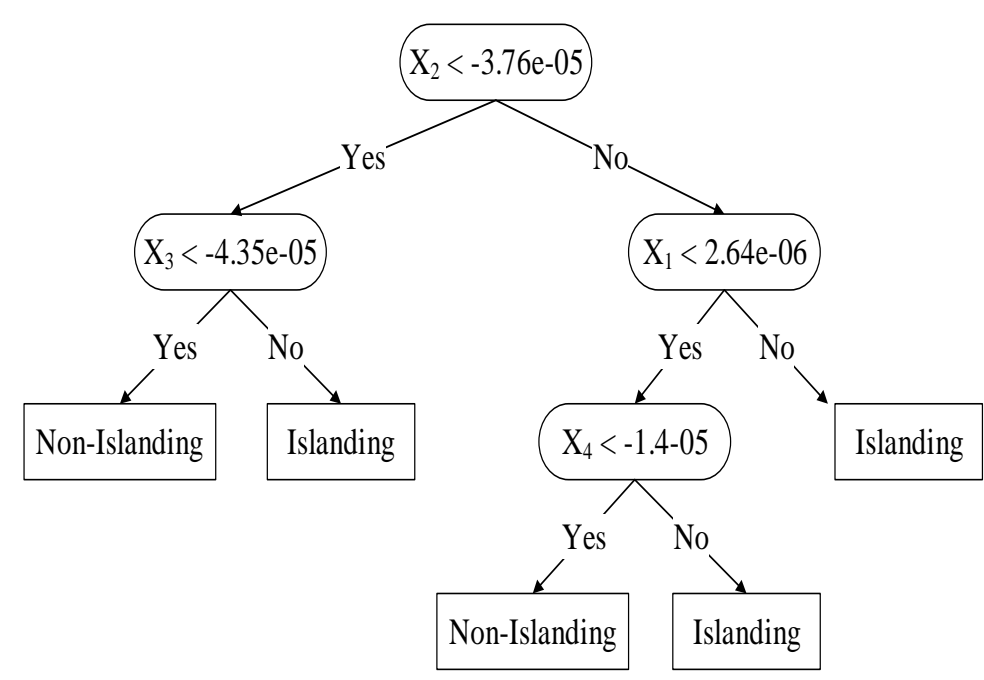

Fig. 9. DT generated during training 

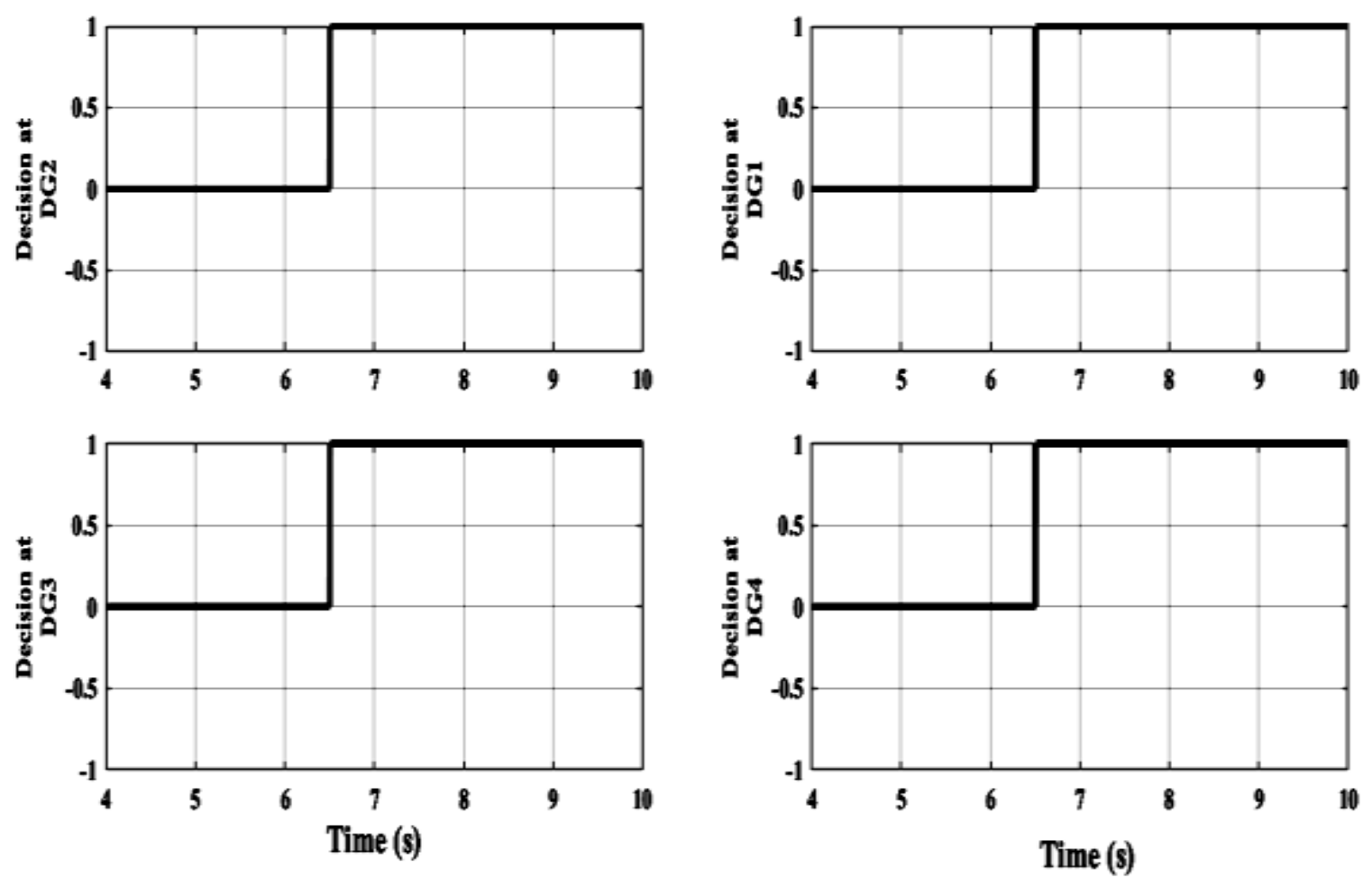

Fig. 10. Islanding decision when $\mathrm{CBO}$ is opened
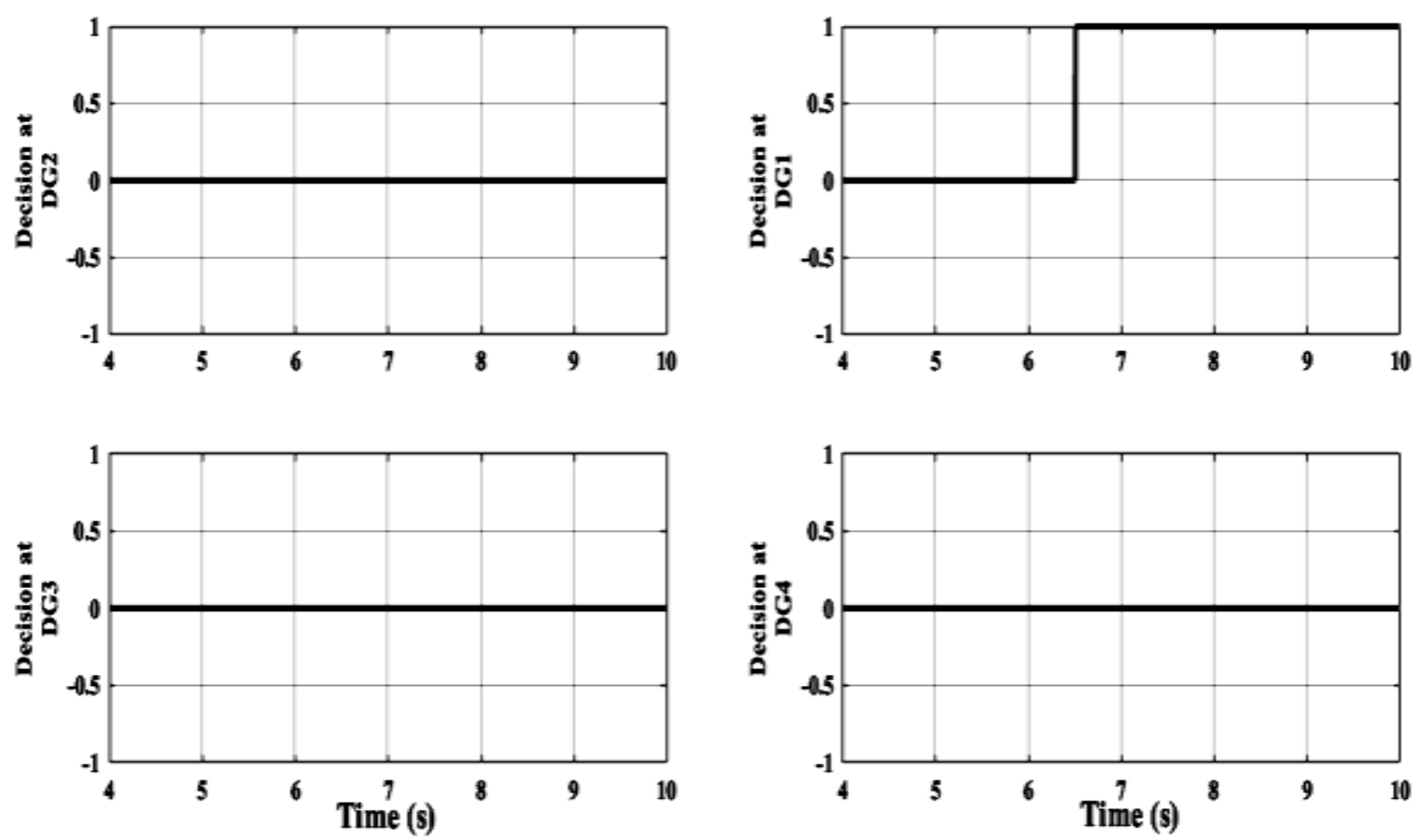

Fig. 11. Islanding decision when $C B 1$ is opened 

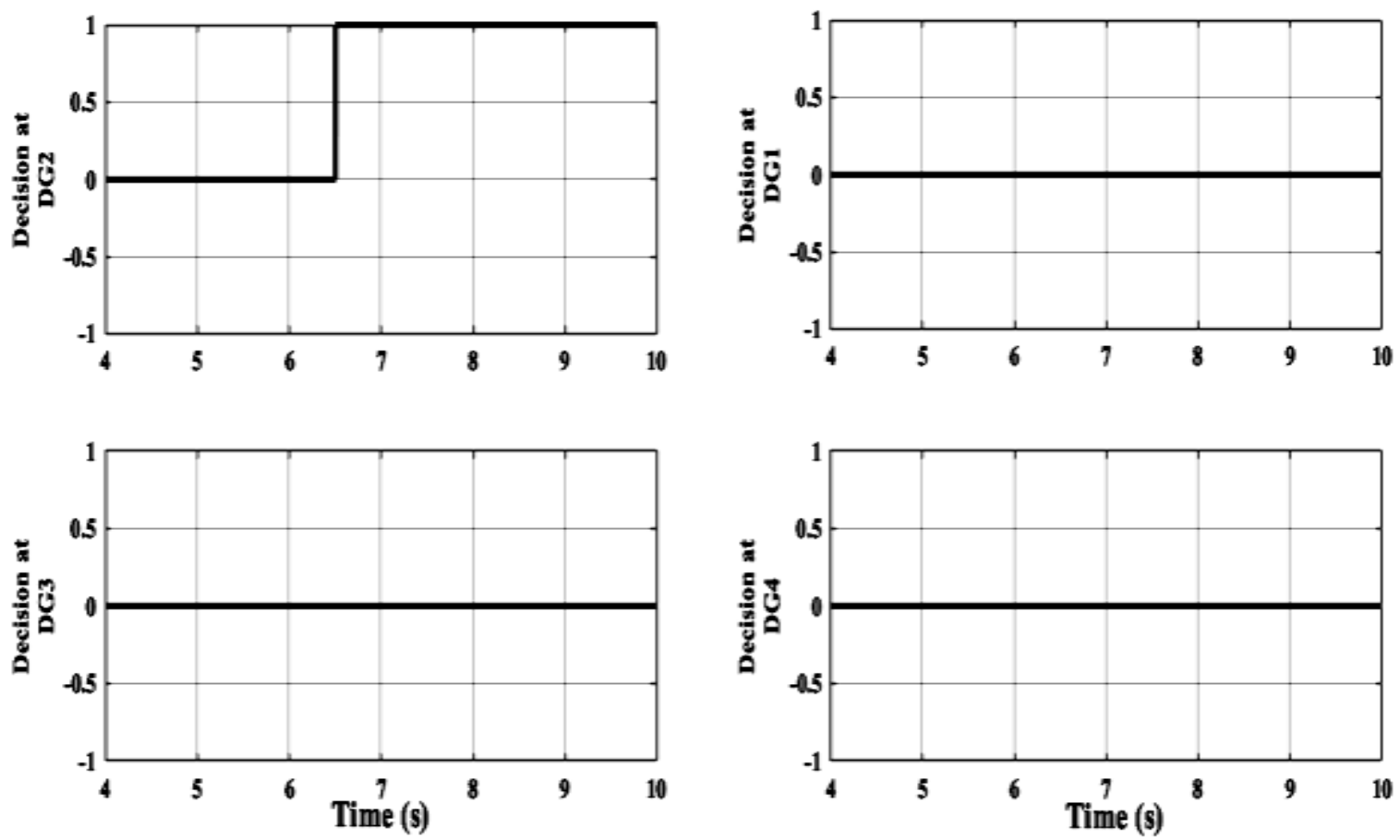

Fig. 12. Islanding decision when $C B 2$ is opened
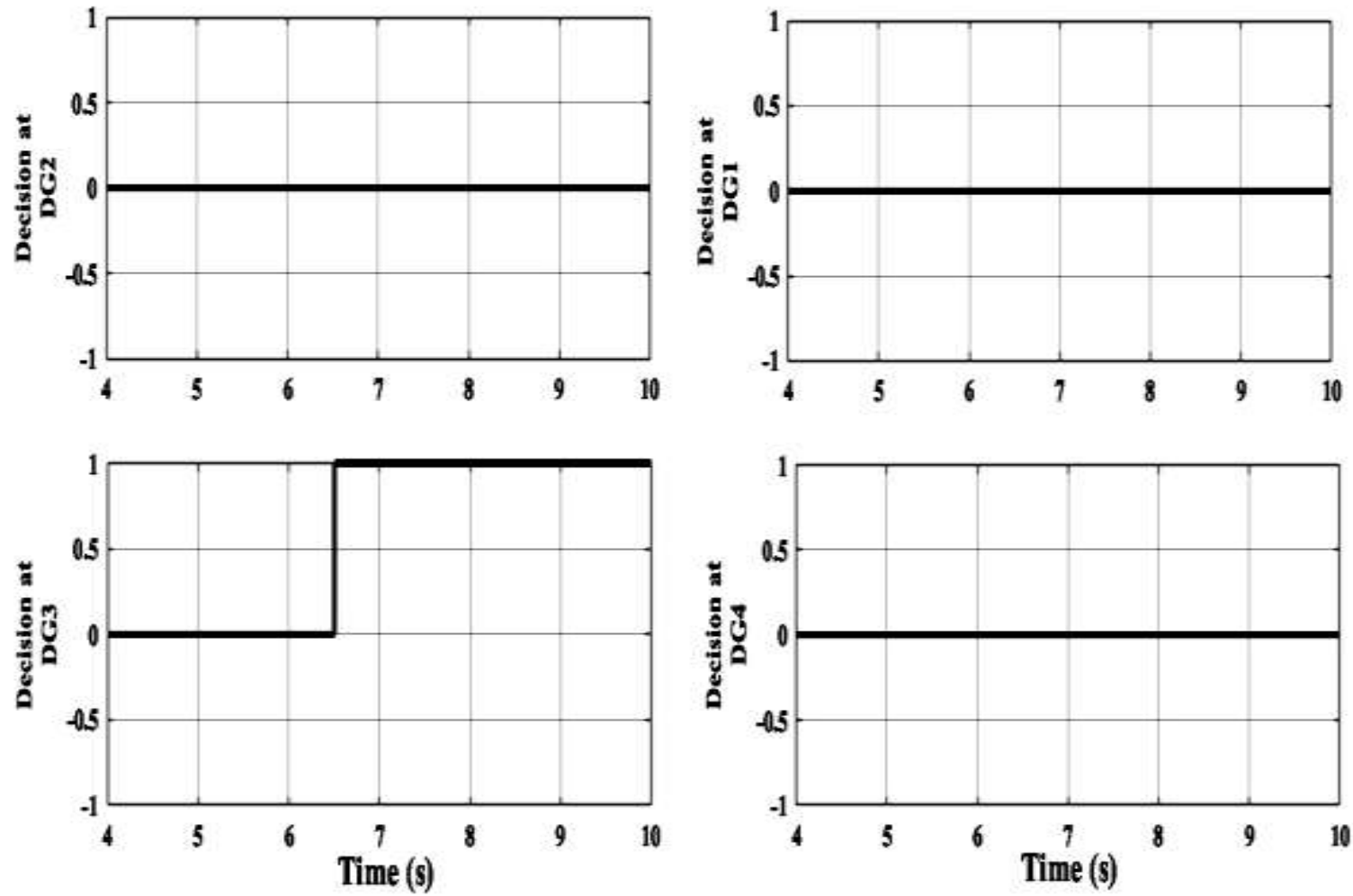
Fig. 13. Islanding decision when $\mathrm{CB} 3$ is opened
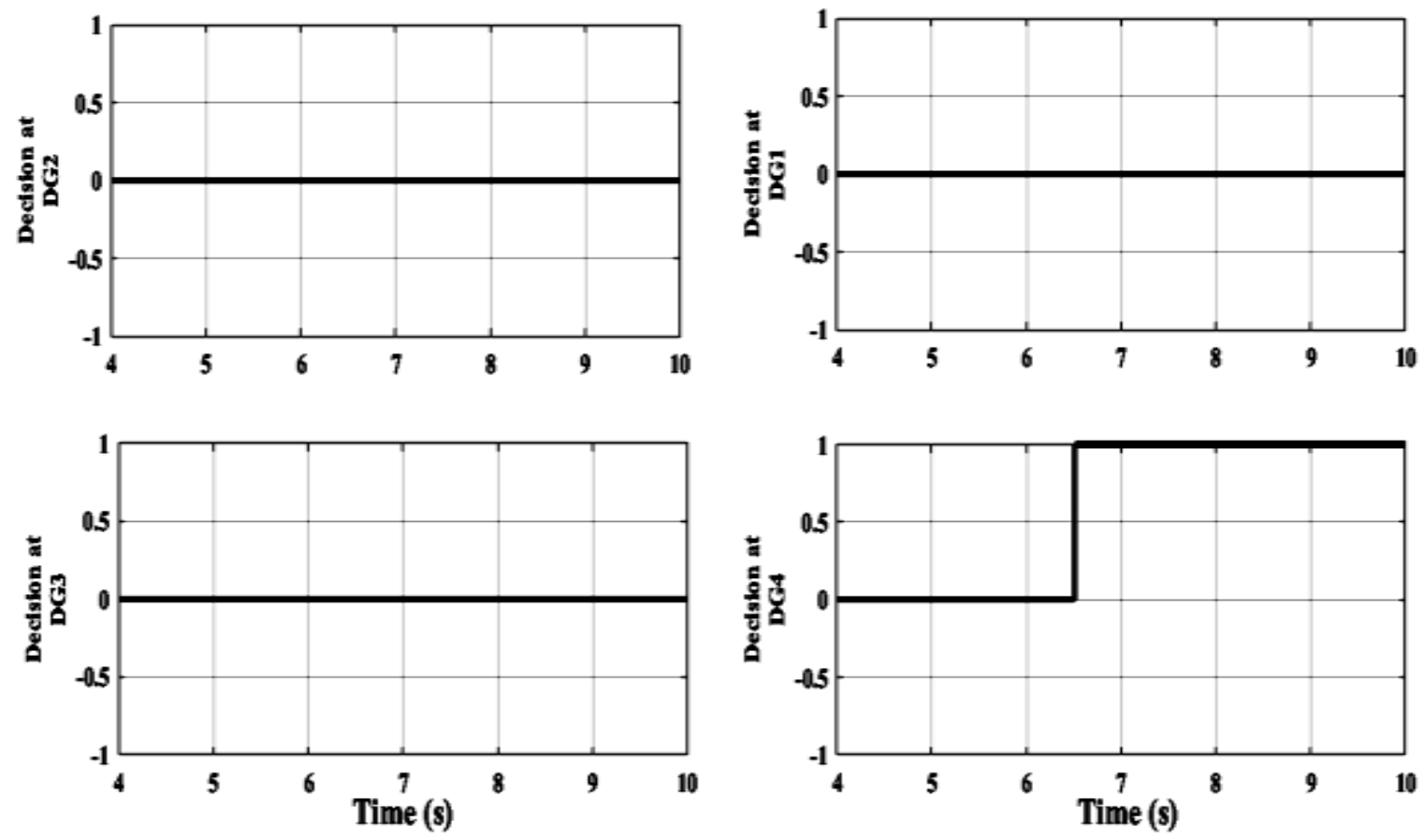

Fig. 14. Islanding decision when CB4 is opened
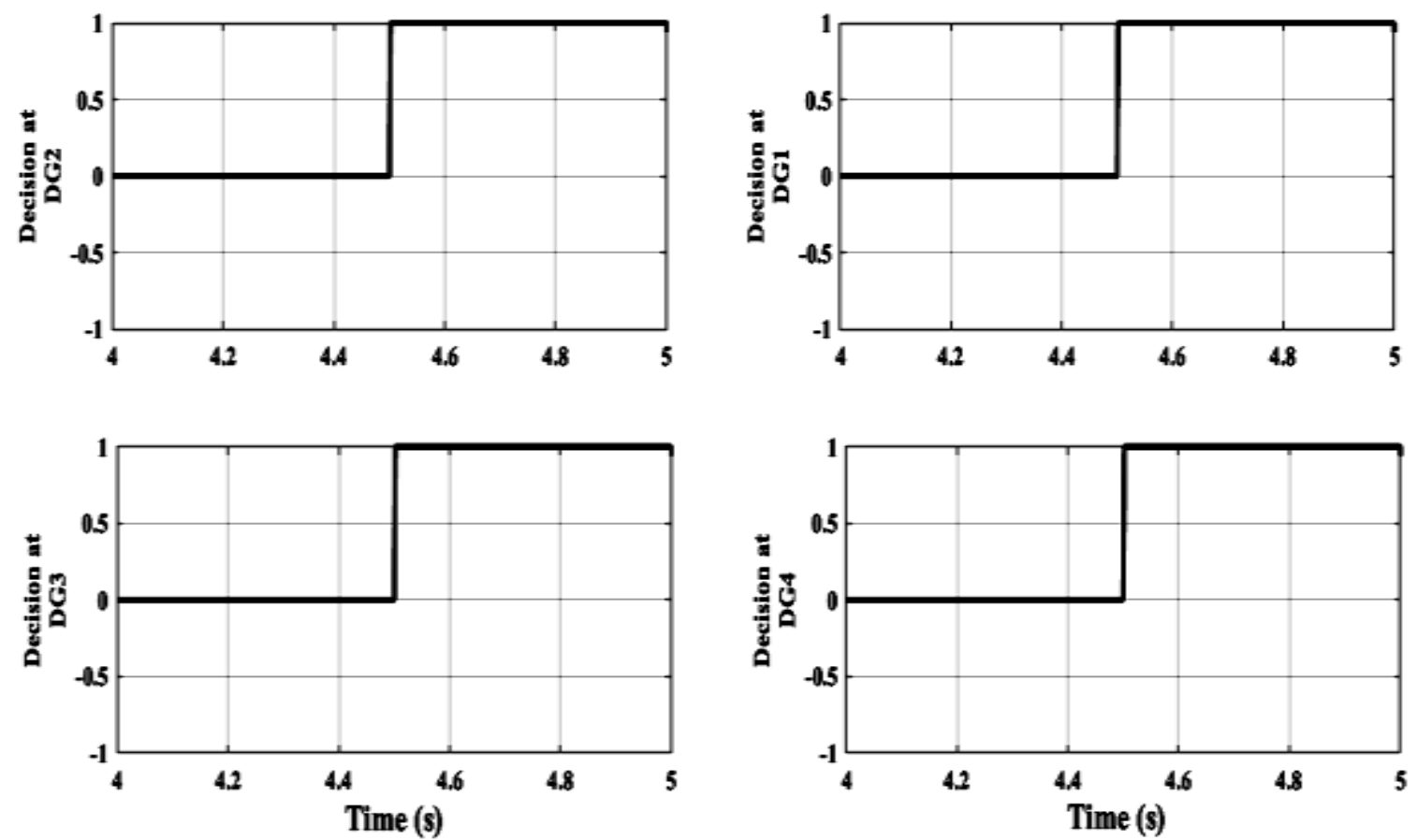

Fig. 15. Islanding decision when a fault occurs near to $C B O$ 

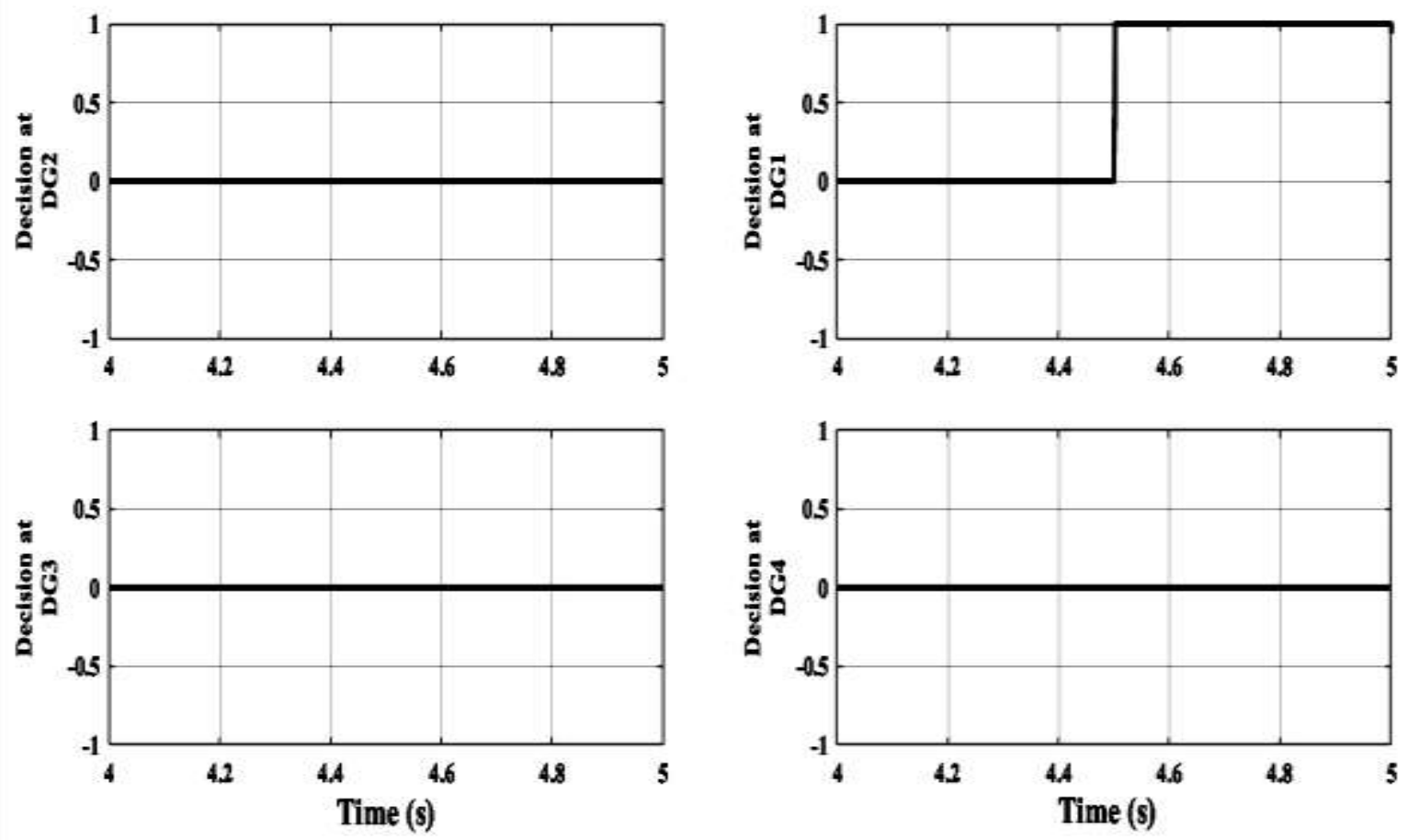

Fig. 16. Islanding decision when a fault is close to $C B 1$
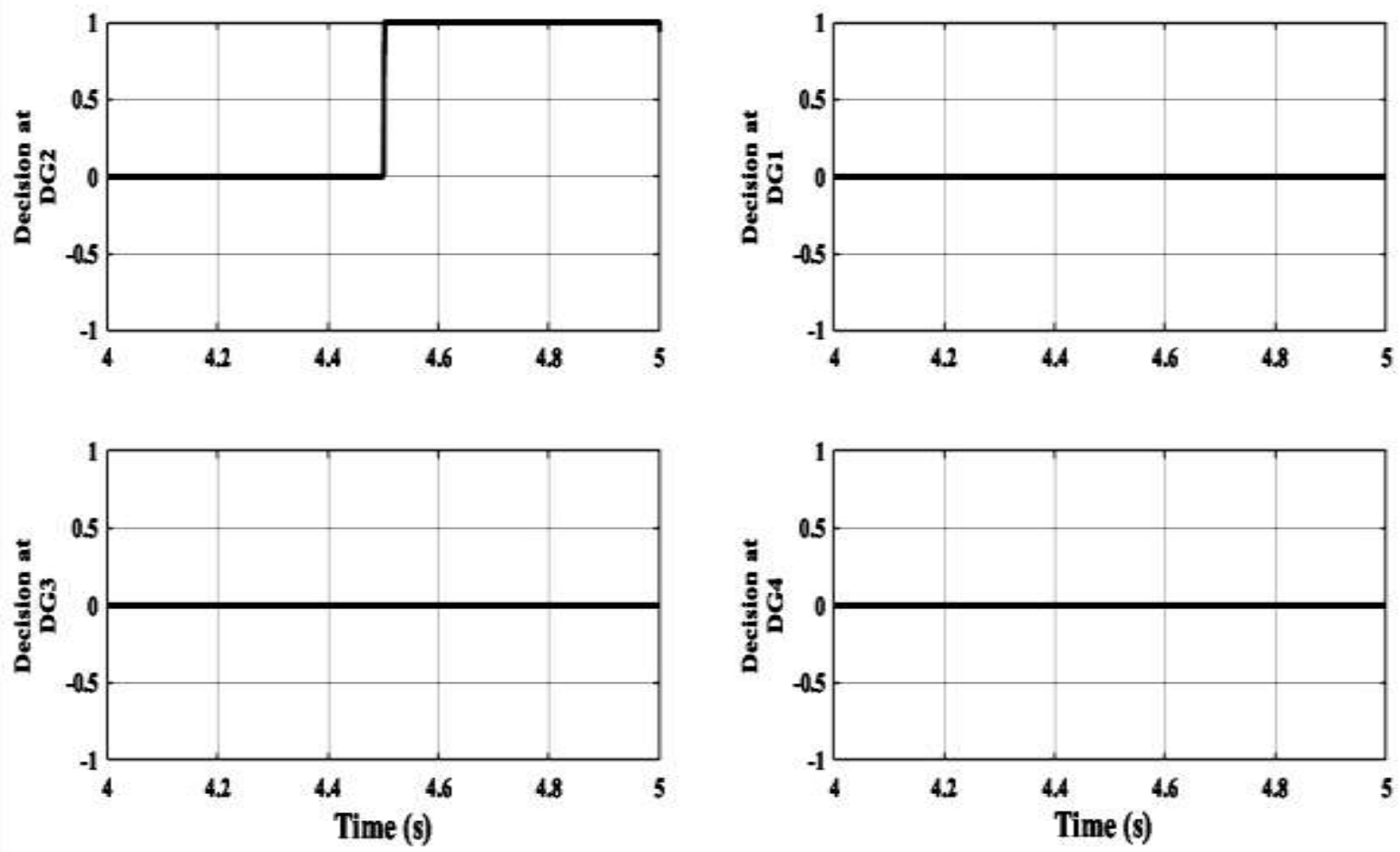

Fig. 17. Islanding decision when a fault occurs near to $C B 2$ 

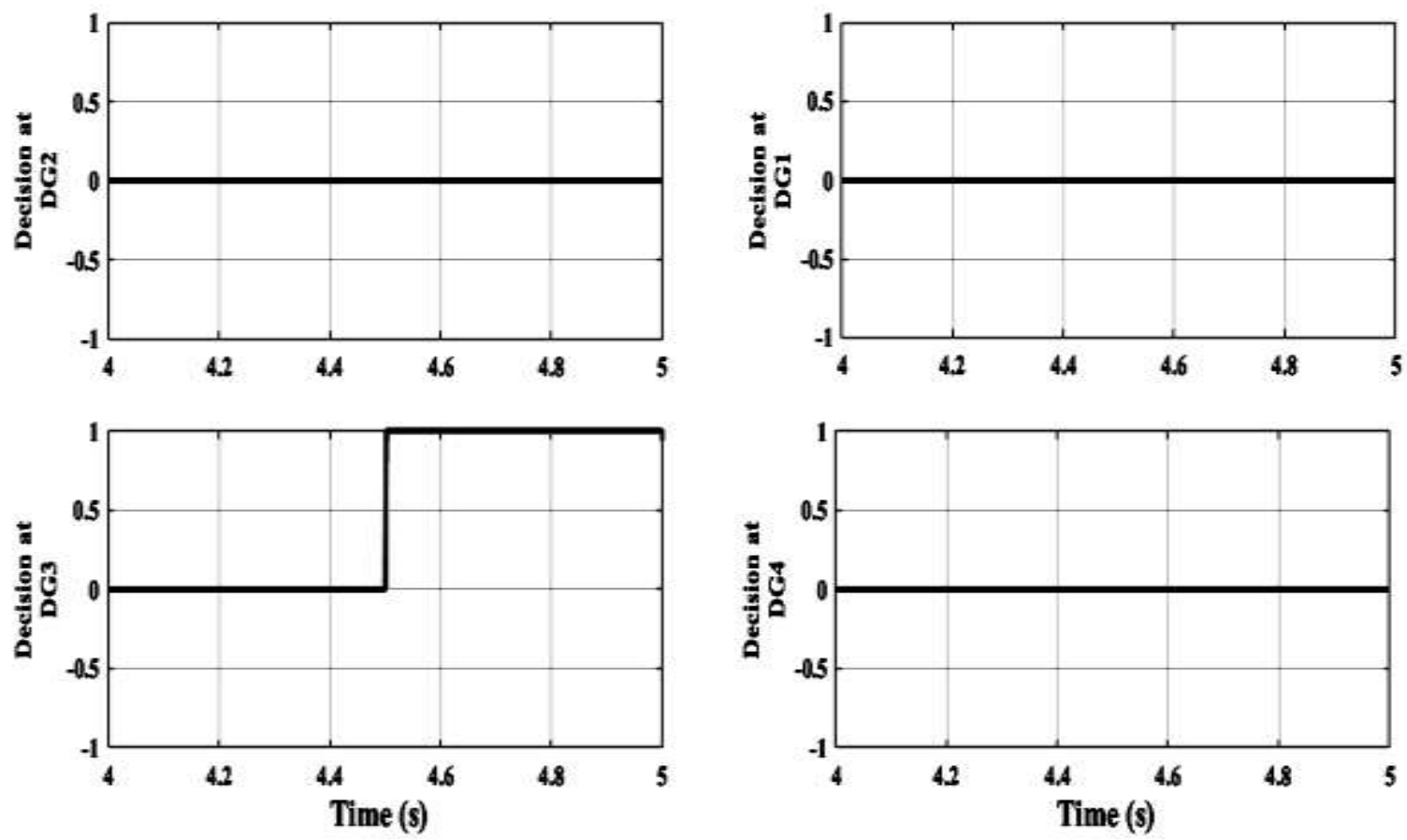

Fig. 18. Islanding decision when a fault occurs near to CB3
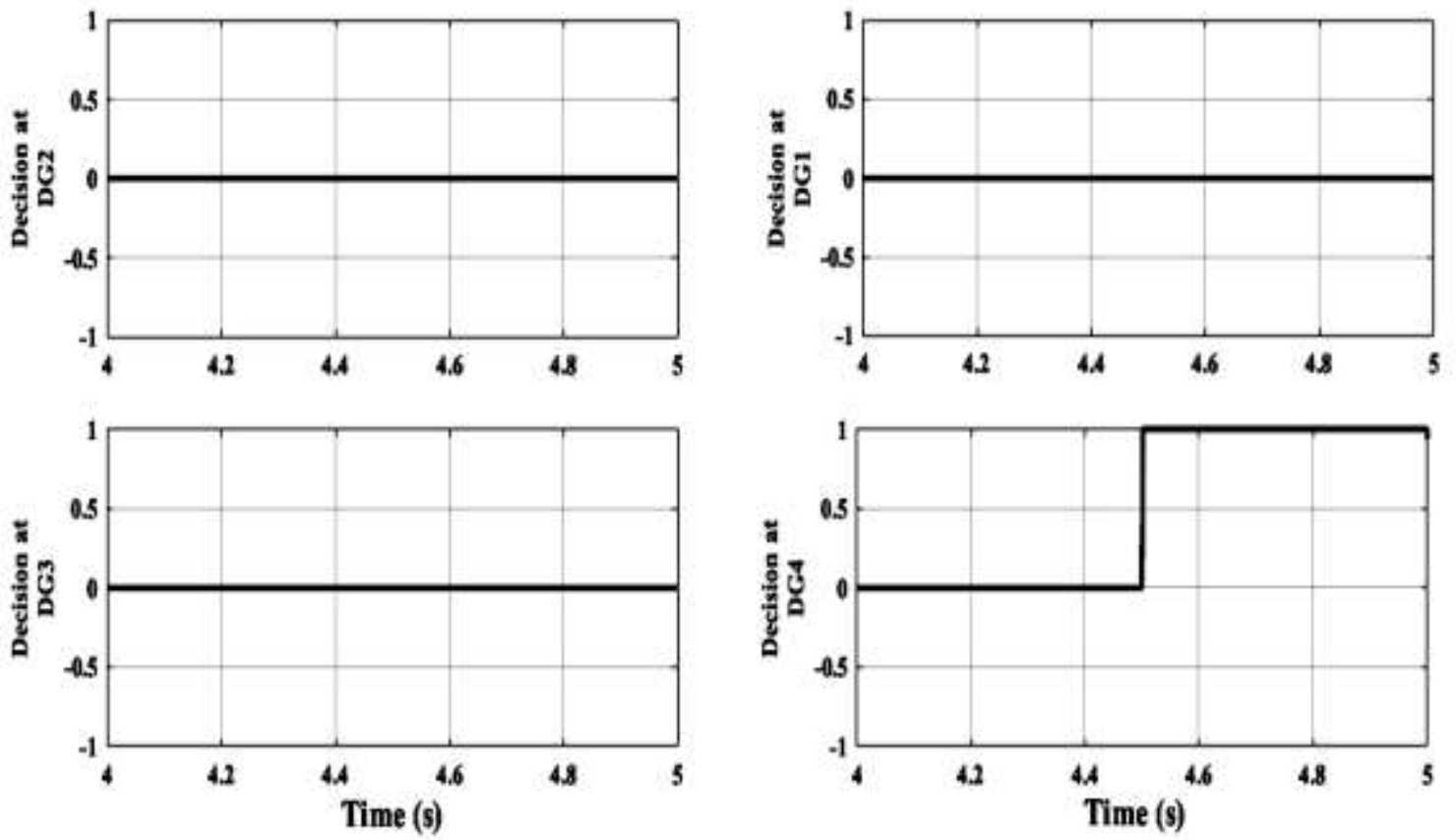

Fig. 19. Islanding decision when a fault occurs near to CB4 
B. Tables

Table 1. Line parameters

\begin{tabular}{|c|c|c|c|}
\hline & Line (Bus-Bus) & $\mathbf{R}(\mathbf{\Omega})$ & $\mathbf{L}(\mathbf{m H})$ \\
\hline $\mathbf{1}$ & DL1 & 4.856 & 34.525 \\
\hline $\mathbf{2}$ & DL2,DL7 & 1.238 & 11.18 \\
\hline $\mathbf{3}$ & DL3,DL8 & 0.7706 & 2.754 \\
\hline $\mathbf{4}$ & DL4,DL9 & 3.2552 & 9.081 \\
\hline $\mathbf{5}$ & DL5,DL10 & 1.701 & 15.36 \\
\hline $\mathbf{6}$ & DL6,DL11 & 0.1803 & 1.628 \\
\hline
\end{tabular}

Table 2. Load parameters

\begin{tabular}{|c|c|c|}
\hline Load No & $\mathbf{P}$ (MW) & Q (MVAr) \\
\hline L1 & 1.50 & 0.70 \\
\hline L2 & 0.40 & 0.28 \\
\hline L3,L8 & 0.33 & 0.15 \\
\hline L4,L9 & 0.53 & 0.20 \\
\hline L5,L10 & 0.45 & 0.25 \\
\hline L6,L11 & 0.60 & 0.43 \\
\hline L7,L12 & 0.67 & 0.37 \\
\hline
\end{tabular}

Table 3. DGs parameters

\begin{tabular}{|c|c|c|c|}
\hline Parameter & Value & Parameter & Value \\
\hline MVA & $3 \& 2$ & $\mathrm{Xd}(\mathrm{pu})$ & 1.56 \\
\hline Voltage (V) & 400 & $\mathrm{Xd}(\mathrm{pu})$ & 0.296 \\
\hline H(s) & 1.07 & $\mathrm{Xd"}(\mathrm{pu})$ & 0.177 \\
\hline Td'(s) & 3.7 & $\mathrm{Xq}(\mathrm{pu})$ & 1.06 \\
\hline Td"(s) & 0.05 & $\mathrm{Xq}(\mathrm{pu})$ & 0.177 \\
\hline Tqo"(s) & 0.05 & $\mathrm{X}_{1}(\mathrm{pu})$ & 0.052 \\
\hline F(pu) & 0 & $\mathrm{Rs}(\mathrm{pu})$ & 0.0036 \\
\hline \multicolumn{3}{|c|}{ Brushless Exciter unit } \\
\hline Synchronous machine & $8.1 \mathrm{kVA}$, 400V, 3-phase, 50Hz, 1500 RPM \\
\hline Transformer & \multicolumn{3}{|c|}{ Diode Rectifier Bridge } \\
\hline Rectifier & \multicolumn{3}{c}{} \\
\hline
\end{tabular}


Table 4. Comparison between proposed approach, NB, and K-NN

\begin{tabular}{c|cccc}
\hline Classifier & Dependability (\%) & Security (\%) & Accuracy (\%) & $\begin{array}{c}\text { Detection } \\
\text { Time (s) }\end{array}$ \\
\hline NB & 77 & 75 & 75 & 0.1 \\
$\begin{array}{c}\text { K-NN } \\
\text { Proposed } \\
\text { approach }\end{array}$ & 95 & 90 & 90 & 0.1 \\
\hline
\end{tabular}

